\title{
The Magical iPad
}

\author{
Janice Honeyman-Buck ${ }^{1}$
}

I know I'm a gadget girl and occasionally buy one that I don't use like my Nintendo DS Lite, but my iPad has turned into an excellent traveling companion, even if it's just to my back porch. It's thin, light, and beautiful. I keep it on a charger within easy reach of anyone in the house for a quick internet search and store all the articles and blogs I want to get around to reading one of these days on it for reading even when out of range of Wireless Local Area Network (WiFi). I did not purchase the $3 \mathrm{G}$ version because I have a $3 \mathrm{G}$ card that supports up to five devices and since it's usually with me in my pocket or bag, I have the internet nearly everywhere, except in the mountains where I spend my summers. This is not a problem, because our cable company happily supplies WiFi to us and through the internet, our Voice over Internet Protocol Phone. It's particularly fun to log on to a free WiFi site in my local coffee shop and watch the envious glances from others.

Everyone knows the iPad is good for surfing the internet, playing games, and reading books, magazines, newspapers, and blogs. But most of us need more than that and within the first 2 months of iPad's release, developers have been working hard to create the tools we need to make this device more than just an entertainment.

iWork for the iPad is a rework of the Macintosh application set containing three separate apps, Pages, Numbers, and Keynote which correspond with the more well-known Microsoft Office applications, Word, Excel, and PowerPoint. Documents from a Windows PC can be moved to the directories or folders for each of these apps using iTunes when the iPad is connected to the computer through the USB cable. When opened on the iPad, they are converted to the iPad app format, maintaining almost all of their original properties (fonts, colors, spreadsheet cells, etc.). I expect this is even more transparent when using an Apple PC. Pages documents may be converted to Microsoft Word and exported back to the PC. For those of us who use Windows, it is a minor disappointment that it is difficult to manipulate Numbers and Keynote documents and convert them back to Excel or PowerPoint; however, by the time this column is published, that may no longer be an issue. All iWork documents can be saved as PDF files.

PDF Reader Pro Edition for iPad is the perfect solution for reading PDF files. PDFs can be loaded on the iPad through the USB file sharing with iTunes, downloading email attachments, or downloading directly from the web using the full built-in web browser. This app implements file management by allowing the user to organize PDFs in user-created folders. The PDF Reader Pro has search capabilities and remembers the last position read when opening a PDF file. This is my favorite application because I can download Journal of Digital Imaging manuscripts to read even when not connected to the internet.

MobileMe is a suite of applications that run on a PC, iPhone, iPod touch, and iPad. These applications synchronize calendars, contacts, and email. In addition, MobileMe has an iDisk where documents are stored in cloud storage for any or all of the devices to access.

The picture below shows my iPad home page. These are my most used apps so they get the first page. They include my iWorks apps, PDF reader, PaperDesk, where I can keep notes and doodles, Evernote which syncs important notes between my computer and my iPad, and iDisk which accesses my cloud storage. I keep my three most used safari pages for SIIM email, iGoogle, and Manuscript Central up front for easy access. Of course my calendar, contacts, videos, and YouTube apps are among the most used. I am currently experimenting with Atomic Web, a browser that allows tabs Fig. (1).

For me, the Kindle will remain my choice for reading most books purchased from Amazon. However, I use the Amazon Kindle app to skim or search through a technical manual or a how-to book on my iPad. I watch full length movies purchased through iTunes on my iPad and some

${ }^{1}$ From the 508 Bramble Fern Ave, Deland, FL 32720, USA.

Correspondence to: Janice Honeyman-Buck, 508 Bramble Fern Ave, Deland, FL 32720, USA; tel: +1-386-3160952; fax: +1-866-6344821; e-mail: Honeyman@ufl.edu

Copyright (C) 2010 by Society for Imaging Informatics in Medicine

Online publication 11 June 2010

doi: 10.1007/s10278-010-9314-5 


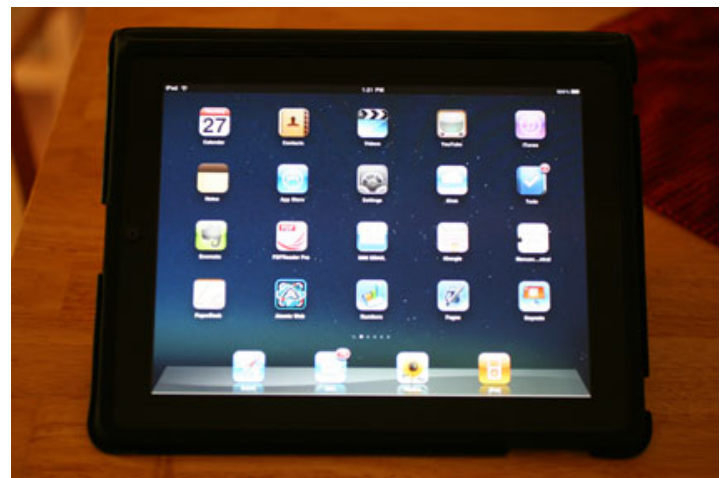

Fig 1. My iPad with my most frequently used apps on my home page.

TV shows. I like music, especially playing it, and the Pianist Pro and Magic Piano satisfy my desire to play with a piano when traveling or just relaxing. I'm looking forward to learning more about these two apps, but if I learn too much I fear I will need to upgrade my existing digital piano to a more current one so I can use the MIDI support.
I've mentioned some of the weaknesses of the iPad, at least for me, the ability to convert from iPad formats back to Windows office format. In addition, the iPad does not support Flash and I am amazed at how many web sites require Flash, for example, Hulu. From the Blogs, I see that Flash developers are hard at work to deliver Flash for the iPad and I expect that we'll see that included by the end of 2010. I like to watch movies on the iPad, but cannot connect the iPad to my TV to watch there. Some output cables have been developed, but even if I could make then work with my systems, they do not currently support the popular Netflix app.

I've had an excellent adventure with my iPad and would like to hear from others' experiences. I will share with everyone on my blog (blogs. springer.com/jdi) and on the Journal of Digital Imaging Facebook page, please feel free to join in the conversation. And now I'm on the lookout for the next cool thing. 